\title{
Risk Management and Behavioral Finance
}

\section{E. Ted Prince}

$\mathrm{PhD}$, Visiting Lecturer at the University of Florida and Visiting Professor at the Shanghai University of Finance and Economics, CEO and Founder of the Perth Leadership Institute, USA.

\begin{abstract}
Risk management is still dated in concept. It assumes a compliance approach. Current risk management approaches have failed in predicting both macro-economic and micro-economic setbacks and disasters. This is because financial metrics, the basis for modern risk metrics, are actually a lagging indicator of risk, not a leading indicator. Risk management needs a new paradigm which is based on leading indicators and which can therefore predict such problems. Behavioral finance provides the framework for a new paradigm for risk management.

The article sets out such a new paradigm. It is based on a distillation of cognitive biases used in behavioral economics and finance. It shows how these can be used to categorize risky financial behaviors according to differing levels of risk. These various levels of risk can be linked directly to financial and valuation outcomes. This provides us with a new way to measure and predict risk based on a behavioral approach. Since behavior is a leading indicator of risk this provides a new approach which takes into account behaviors which are normally not captured in risk approaches. This opens up a new discipline of behavioral risk management. This is needed to correct for the lack of behavioral data in current approaches.
\end{abstract}

Key words: risk, behavioral finance, financial signature, cognitive biases, irrationality.

JEL Clasification: B and G.

(C) The Author, 2018. This article is published with open access at Sumy State University.

\section{Introduction}

\section{Part 1. Conventional Risk Approaches Not Effective}

The Economic Crisis Was Also a Risk Crisis. We had a major economic crisis in 2008-2010. This was not due to inadequate concern about risk and risk management (Michelle Park Lazette, 2017). Every financial institution in the world had a risk management strategy and numerous risk management officers. Each had apparently sophisticated risk models. These were backed up and supported by also apparently sophisticated risk models in the central banks and government regulatory agencies. All of these failed (Douglas W. Hubbard, 2009).

Following the financial crisis the government has focused on strengthening risk controls and approaches. This has seen the passing of Dodd-Frank and other new laws. Banking and financial company supervision has been strengthened. New stress tests have been devised to see if banks are strong enough under new rules. Laws in regards to "too big to fail" have been passed (John Weinberg, 2013). This has definitely led to many financial institutions taking less risk.

But it is not at all clear that is has lessened overall risk in the financial system or even in its component companies and institutions (Mark A. Calabria, 2015). Deutsche Bank is now touted as being the New Lehman (Deutsche Bank, 2016). Banks in Europe, especially in Italy, but also in Germany and other countries still appear to have, if anything, heightened risk (Gerold Grasshoff, 2018). Unprecedentedly low interest rates even negative rates - may well have increased overall system risk by creating new types of asset bubbles and new types of system risk whose import is still not fully appreciated, if at all (Macroprudential policy issues arising from low interest rates and structural changes in the EU financial system, 2016).

It is looking increasingly like the risk management approaches that have been devised as a result of the financial crisis are already not up to the job of confronting the new global situation of low and negative interest rates, the new global banking situation and other changes. It is increasingly looking like the risk management approaches newly developed is in retrospect not unlike generals always fighting the last war.

Some of the problems in risk management that emerge from this review include the following: 
1. New types of asset bubbles in stocks, real estate and commodities (Silvio Contessi, 2015)

2. Banking crises in Europe and possible knock-on effects in the US (Knowledge@Wharton, Is Europe Headed for a Banking Crisis in 2017?, 2017)

3. Unintended consumer behaviors such as increased savings resulting from negative interest rates (Ioana A. Duca, 2016), inter alia.

4. Legal challenges to regulatory compliance that makes it less effective.

5. New types of exposures resulting from new types of systems and new types of hacking and cyber-exposures.

The classical definition of business risk management is the process of identification, analysis and acceptance or mitigation of uncertainty in investment decisions (Simona-Valeria Toma, 2012). Ultimately, from a business perspective, the mitigation of risk means taking steps to ensure that the process of capital creation and profitability proceeds as intended. From the perspective of a single company, risk increases as the probability of not meeting profitability and capital creation targets decreases.

So we can take the definition of risk as being factors that lead to profitability and capital creation targets not being achieved. Classical risk analysis has a number of interlocking approaches that review all the many types of factors that would lead to profitability and capital creation targets being missed (David W. Blackwell, 2006).

But there is one factor that has never been formally considered in these analyses. That is behavioral risk. That refers to behavioral factors that would systematically lead to profitability and valuation targets being achieved. Factors that would be included could include criminal behavior. It could also include behavior that is definitely not criminal but that results in profitability targets not being achieved such as management extravagance or overspending. There are many factors in this category. But none of these are even formally included in modern risk analyses.

Behavioral finance has now emerged to provide us with new tools for behavioral analysis in a financial context (Hersh Shefrin, 2015). So far these have not been included in current risk models except in the most general and qualitative way. What we need is risk models which include formal reference to behavioral factors which affect financial, profitability and valuation outcomes and which can predict these outcomes in a quantitative manner. This would for the first time provide a useful approach to risk analysis and profitability impacts.

This paper shows such a model. It is based on extensive research. It is based the assumption of behavioral finance that many decisions are not taken under conditions of classical rationality and indeed might be very irrational. The model integrates the factors of cognitive bias that systematically impact all decisions including financial decisions and show how this impacts financial and profitability outcomes. It therefore provides risk estimate based on precise prediction of financial outcomes under varying behavioral scenarios. It thus fills a huge gap not presently addressed in modern risk analysis.

\section{Classical Risk Approaches Are Based on Dated Thought Systems}

Current risk analysis can be categorized into four approaches. These are:

1. The financial approaches

2. The technical and systems approaches

3. The compliance approaches

4. Situational approaches

\section{Financial Approaches}

These use the tools of modern economics and finance. All of these assume that people make rational decisions in finance and economics. But we know that this assumption is false (Dan Ariely, 2009). People make decisions, including financial decisions, under conditions of mixed rationality.

Of course, in their own minds, they are always making rational decisions. But we know for sure that many of their decisions are affected by cognitive biases of which they are not aware that result in decisions not always being rational, even though they think that they are. People will even make obviously irrational decisions but rationalize them to defend them with others.

In fact we also know that some of the markets people are particularly effective in rationalizing decisions that are effectively irrational and persuading others that they are rational, even when they are not. 
We also know that some of the smartest people in companies, regulatory agencies, central banks universities are also subject to this same bias, even though they think they are not. This is why, for example, we know that central banks are particularly ineffective at forecasting recessions and that even the Federal Reserve did not predict the financial crises until well after it had started (Speech by Chairman Ben S. Bernanke, Implications of the Financial Crisis for Economics, 2010).

There are four financial factors in financial risk analysis. These are:

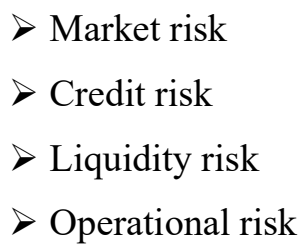

All of these are subject to the rationality criterion. The people who conduct these analyses are generally trained in the classical disciplines of economics and finance. They are always having received no training in behavioral analysis or in behavioral economics and finance. Even if they had received some training in behavioral economics and finance until recently there have been no models that formally link different behaviors to precise financial outcomes that can be measured and quantified.

\section{The Technical and Systems approaches}

This is subject to similar factors as above. In looking at technical approaches, hacking and cyber-issues again the assumption of rationality applies. However if indeed there is a spectrum of behaviors in all humans which influences decisions and the outcomes of these decisions, then these same behavioral factors can and should be applied to technical, systems and cyber issues. So far risk approaches have just assumed that all players have rational and homogenous behaviors, which is simply not the case.

\section{The Compliance Approaches}

Much of modern risk analysis is based on compliance approaches. But we know that often compliance systems are only effective at the margin (Piotr Kaminski, 2017). Compliance approaches are invariably based on legal rules and paradigms and not on behavioral paradigms. They thus miss much if not all of the behavioral motivations of players who are actors within compliance subsystems that are supposed to reduce, mitigate or prevent risk. Unless compliance regimes take behavioral factors into account, and especially the financial outcomes of different types of behaviors, compliance systems will continue to be viewed with skepticism by many players in the private and public sectors alike.

\section{Situational Approaches}

These approaches focus on issues such as political and sovereign risk, Black Swan events and "unknown unknowns". In this area behavioral factors are indeed often involved. But these behavioral factors are invariably psycho-analytic-based, not behavioral-finance based. In other words, they give us some ideas about the risk from emotional behaviors but they can't give us any but the most broad-brush idea of financial outcomes and impacts, especially in quantitative terms (Terje Aven, 2015). What, for example, is the impact of a terrorism event on a particular company with a particular CEO and management team? We need to know more than how they will react. We need to know the like impacts in quantitative terms on profitability and valuation. That will provide us with a useful risk analysis and set of financial impact metrics.

\section{Most Risk Approaches Have a Process Bias}

What do we mean by this? We mean that most risk analyses are based on a check-the-box approach. The presence or absence of certain factors will lead to risk estimates being reduced or increased (Editors: Anthony Tarantino, Governance, Risk, and Compliance Handbook: Technology, Finance, Environmental, and International Guidance and Best Practices, 2012).

But they don't take into account the human factor. They don't attempt to give us quantitative estimates of increases of declines in profitability and valuation based on the behaviors of particular CEOs or management 
teams. That means that in investment scenarios for example, they are almost totally useless. That occurs because, within these models, there is no room for the precise individual or teams that is running the show. Once these risk models have been constructed, it doesn't matter who the CEO or the team is; it will work if you add any CEO no matter her background, behaviors or proclivities (Sridhar Ramamoorti, 2016).

\section{They Also Have Fundamental Systemic Flaws}

With the wisdom of time, hindsight and a lot of experience in the field we can now see that the classical risk canon incorporates systemic flaws. These include the following:

1. Excessively inappropriate focus on financial analysis skills

2. No focus on behavioral issues

\section{Ignores decision-making biases}

Financial analysis skills have become such a part of risk management that it might seem strange that this would be listed as a systemic flaw. Of course, financial analysis skills are vitally important in good risk. But the problem has been that the focus on financial analysis skills has been at the expense of approaches that focus on job performance and risk outcome. But even there, relatively recent meta-analyses by risk experts have demonstrated unequivocally that personality assessment results are not correlated whatsoever with risk performance or job outcome (Morgeson, 2007).

This does not mean that a focus on financial analysis skills is wrong or misguided. Nor does it mean than there should not be development of risk analysts aimed at improving the vital financial analysis skills needed in risk. What this means is that there has been a systemic failure in risk study where the focus on financial analysis skills been at the expense of questions of risk outcome and performance and the skills that are related to these.

Behavioral Drivers: It is clear that ultimately good risk must result in increased profitability or company value. Most times this will be reflected in business and financial metrics such as profitability and company valuation. But until very recently there has been no work whatsoever on the direct behavioral links between risk and business and financial outcome and the associated financial and valuation metrics. We will explore this work further below.

Risk approaches that focus on personality, competencies and team dynamics are all useful in themselves. However they do not link with the financial and valuation outcomes in a direct and measurable way in a manner that is desired and required by shareholders. These risk approaches focus on the competencies that lead to better social and interpersonal functioning, which is fine in itself but does not address directly the links between risk and profitability and competitive outcomes (George P. Hollenbeck, 2006).

When boards and shareholders examine the performance of a CEO and his management team, their attention will ultimately be directed to the business and financial metrics rather than the behavioral drivers of these metrics. Until risk approaches integrate these concerns directly into their ambit, this issue constitutes the major systemic gap in modern risk approaches.

Ignores decision-making biases: The classical leadership canon makes a distinction between rational leaders and those with personality pathologies such as narcissism. But the leaders with pathologies might still have great financial outcomes and the leaders without them might not (Kari Olsen, 2013). But this canon has not addressed the issue of why leaders who are rational may still underperform or even fail badly while those who are not especially rational might perform well. The behavioral finance model set out in this paper can explain and even predict that. Modern risk analysis cannot. This is a huge gap.

In effect the classical risk canon equates rationality with good performance. Yet, as we shall show below, the existence of universal cognitive biases in all humans and in all leaders and managers - and yes, risk analysts - means that much decision-making is fundamentally flawed (Richard L. Priem, 1995). This has not been addressed at all in the classical risk canon.

This, along with classical economics and finance, assumes that rational actors will have the best performance and that lack of performance can be addressed merely by ensuring that the leader has more information and knowledge at his disposal. But this again is simply not true. We cannot assume that having access to more information will result in better decisions. Again this is a glaring gap in modern risk analysis. 


\section{Part 2. They Require Linkage to Financial Behavioral Factors}

\section{Shareholders Want to Know Where's the Beef}

Risk in modern organizations is required to control and, where possible, improve profitability and valuation. This applies to both public and private companies alike. Scarce capital is used by these organizations and the ability to make it more effective is a key requirement of modern risk approaches. Leaders who do not do this are routinely removed in order to find those who can. Risk analyses must aim to drive better financial and valuation outcomes. The inverse of risk is profitability and capital accumulation. So ultimately risk management is directly in the interests of shareholders and investors.

Yet, as we have shown, the classical risk canon signally fails to do this. Risk assessments focus on financial analysis skills and certain process competencies. While these are relevant to risk, they do not define its success in modern organizations. Success in modern organizations is ultimately financial and valuation outcome. To be precise, if an organization gets a better valuation outcome than its competitors, then its risk has performed better than their's. Nothing else counts as long as the organization operates ethically and is reasonably managed.

We have already set out the major criteria in the classical risk canon for risk success. These are financial analysis, technical and systems analysis, compliance analysis and situational analysis. The bases are processoriented and not behavioral. They tend to be technocratically - rather than behaviorally-focused. So they lack the intellectual underpinnings which focus on the necessary behavioral and cognitive biases in the building of financial valuation and maximization of capital creation.

The overwhelming problem with modern risk approaches is the failure to link directly with behavioral and cognitive biases in decision-making which link directly with financial outcomes. The classical risk canon cannot help this since it has intellectual foundations that are largely unrelated. This is seen in the intellectual base which focuses on decision-making under conditions of rationality.

In order to build the necessary linkages, we need to turn first to the disciplines of economics and finance. These are disciplines which experts in conventional risk and financial analysis are generally comfortable with.

\section{Traditional Economics and Finance Assume Perfect Rationality}

Classical economics has a history dating back to the $19^{\text {th }}$ century. The classical economists ranging from Adam Smith to Keynes built formal models based on a very particular psychological platform. That platform assumed that individuals and corporations are rational economic actors. This allows a sophisticated structure of models to be built.

At the microeconomic level it allows for the development of utility theory. This in turn allows for the development of choice theory for both consumers and corporations involving indifference curves and the like. The assumption of rational economic actors underlies the full range of microcosmic topics ranging from pricing, demand theory, consumer choice and more latterly decision and game theory. Latterly these theories have been extended to modern work in the areas of options and options prices, derivatives and synthetics.

At the macroeconomic level, the assumption of rationality allows for the development of theories regarding a wide variety of topics including interest rates, money supply, and consumer demand. These in turn have been built up into models of growth which incorporate linkages between investment and consumer behaviors, savings and investment, interest rates and money supply. It is from this base that the idea of the efficient market hypothesis arises. All of these models depend on the assumption of rationality to work.

Economists have always known and accepted that these theories are an approximation to the real world. The models work fairly well when conditions do not change much. However it has become increasingly clear that the classical economic models do not work at all in the following cases:

When conditions change significantly

$>$ In predicting major changes in corporate valuation

$>$ In predicting macroeconomic inflection points and crises

It is increasingly being seen that classical economics tends to work best when conditions do not change much, and when rational behaviors dominate the market. When these conditions are infringed, then classical economics and finance break down and cannot predict the outcome (Schilirò, 2011). 
In this sense, classical economics and finance are reminiscent of classical risk models. In both, rationality is the basis for the model to work. When irrationality enters, the models break down. In both cases the models cannot predict what happens if most behavior is not rational. So the classical theories have major restrictions that limit them to only being valid in particular, relative narrow situations.

That is one reason why risk approaches have not been able to incorporate the new behavioral disciplines in order to link financial and business outcomes. These classical disciplines assume a level of rationality that is just unrealistic in risk and thus prevents them being used for real-life risk situations. For economics and finance to play a part in linking risk with business outcomes, they must be able to able to address irrationality in decision-making.

\section{Irrationality is Now Being Addressed through New Behavioral Disciplines}

We have always known that managers and decision-makers, indeed all humans, have biases. The trouble is that they are difficult to model in particular situations. We may know that a leader or any financial actor tends to under-spend or over-spend, but predicting that in advance for a particular leader or company is difficult and requires models that have only recently commenced development.

We know that there are numerous other types of biases that affect decision-making. However these had never been cataloged or their effects formally described. So although theorists knew that rationality was not really realistic, a formal platform had never been developed to model those biases.

The issue has been how to link irrationality - or to be more accurate, mixed rationality - in decision-making with economic and financial outcomes. The first steps in this process have been made with the emergence of the new disciplines of behavioral economics and finance. These disciplines formally relax or drop the assumption of rationality in building models of economics and financial phenomena. For the first time we now have a language and models that link financial outcomes to real-decision-making in the real world.

This allows us for the first time to formally link decision-making that is not necessarily rational to financial and business outcomes. Since this is what risk analysts do, we now have for the first time a set of models that can use be used to describe and predict risk behaviors and outcomes, in business and financial terms (Sveinn Vidar Gudmundsson, 2013).

\section{Behavioral Economics \& Finance Open Up a New Risk Approach}

Their Newness Explains Why Risk Approaches Haven't Caught on Yet: The field of behavioral economics and finance can be said to have received formal recognition of their intellectual coming-of-age with the award of the 2002 Nobel Prize for economics to Daniel Kahneman of Princeton University for his work into behavioral economics (Daniel Kahneman, 1979).

Research into this field commenced in the 1960s with work by Nobelist Herbert Simon and expanded in the 1970s with the development of what is called prospect theory. Prospect theory is a theory of decision-making where decisions have uncertain outcomes and people have different ways of evaluating gains and losses. These decisions are not necessarily financial in nature although much of the work that surrounds them is concerned with economics and finance (Konstantinos V. Katsikopoulos, 2014).

The research has been motivated by the increasing divergence between prediction and reality in the fields of economics and finance. It had become increasingly clear that economies and finance were not approximating reality and that a new approach was needed.

For the first time, what we term "irrationality" has been formally opened to research and investigation in the fields of economies and finance. These new fields provide comprehensive explanations and models as to what constitutes irrationality in decision-making and show how it leads to totally different types of economic and financial outcomes to those predicted by classical theories.

Behavioral Disciplines Explain Much That Was Hitherto Inexplicable. The new behavioral disciplines have far-reaching ramifications for most business and economic areas. .They impact decision-making, human resources, strategy, marketing, consumer choice, advertising, talent development and human resources, investor behavior, and stock market behaviors to mention just a few. So far the impact is at an early stage since the fields are still very new and practitioners of these disciplines are only slowly coming to grips with their many implications. 
McKinsey has made some insightful observations on this subject (McKinsey, 2010). They cite some of the problems that are caused by the lack of understanding of behavioral strategy. These include failed mergers and acquisitions, large projects usually being over-budget and strategies usually ignoring competitive responses or getting them badly wrong.

This research concludes that, contrary to what one might expect "good analysis in the hands of managers won't naturally yield good decisions..." (McKinsey, 2010) This of course flies in the face of conventional approaches that assume if we are smart, reasonably educated and have the right data, we will have a very good chance of making a good decision that will have a beneficial outcome. It explains why, to the contrary, so many decisions at all levels of management, informed by the best analysis possible, so often yield poor outcomes.

As one might expect from a consultancy that focuses on strategy, the McKinsey research has a lot to say about the implications of behavioral disciplines for strategy development. Their work suggests that cognitive biases affect the smartest executives in the most important strategic decisions in the best companies.

For risk this has critical implications too. It suggests that most risk analysts are unaware of their biases and therefore are not in a position to compensate for them. In hiring, developing and promoting risk analysts, those who participate in these processes cannot identify these biases and predict their impact on the quality of risk of the managers they are promoting.

In sum, if anyone ever wanted a good explanation why so many risk analysts fail, and why so many boards and risk experts tend to make so many bad hires, one has only to look at the previous formally unrecognized issue of cognitive biases (Tomer Hochma, 2017).

The behavioral disciplines are not just about finance and economics; they are ultimately about risk and how flawed the outcomes of risk analysis are likely to be if these behavioral factors are not taken into formal account. The behavioral disciplines provide a new perspective on any type of decision, be it economic and financial or otherwise.

In Categorizing Types of Cognitive Bias. In their new theory, termed prospect theory, Kahneman and Tversky in the late 1970s identified and set out a number of cognitive biases that routinely impact decisions, both financial and otherwise (Judgment under Uncertainty, 1974). What they pointed out was that these biases had never been taken into account in classical economics and finance (Richard A. Posner, 2013). The existence of these biases meant that the rational decisions assumed by classical theorists were very unlikely in the case of many if not most decisions.

It is not the intention of this article to provide a primer on behavioral economics and behavioral finance. However it will help to provide some examples of these cognitive biases. In their book (Daniel Kahneman, 1979) some of the principal biases mentioned were as follows:

Framing effects: The way a problem or decision is presented to the decision maker will affect their action.

Sunk cost fallacy: The tendency to continue to invest in something, even if it is a hopeless case

Status quo bias: people prefer that things remain the same, or that things change as little as possible, if they absolutely must be altered.

Endowment effect: people value a good or service more once their property right to it has been established.

Loss aversion: people's tendency to strongly prefer avoiding losses to acquiring gains. Some studies suggest that losses are twice as powerful, psychologically, as gains

Anchoring effect: the tendency to rely too heavily, or "anchor," on a past reference or on one trait or piece of information when making decisions

Overconfidence effect: excessive confidence in one's own answers to questions. For example, for certain types of question, answers that people rate as "99\% certain" turn out to be wrong $40 \%$ of the time.

$>$ Survivorship bias: concentrating on the people or things that "survived" some process and ignoring those that didn't, or arguing that a strategy is effective given the winners, while ignoring the large amount of losers.

There are numerous other cognitive biases that have been identified. These biases are not just ones that have been observed. All of them have been tested through actual experiment so that the situation can be controlled scientifically. So the existence of these biases has been scientifically confirmed, measured and manipulated to see their effects in many different situations. 
It will be clear that these cognitive biases operate within the decision-making environment of any company. So these cognitive biases must be a key driver of problems in these companies. They are therefore an important microeconomic factor. Of course, this also means that they are a crucial factor in risk analysis and management both for companies, regulators and financial actors of any sort.

Since these biases operate in all companies and in all organizations, including in nonprofits and governmental organizations, they also operate at the macroeconomic level. This means that they impact demand and supply at the macroeconomic level, and in the areas of growth, trade and investment. Again this impacts risk at the national levels as well as the international levels.

It does not take a great leap of imagination to see that these cognitive biases are crucial in assessing and studying risk analysts and the outcome of the decisions. Yet none of this way of thinking has yet impacted risk approaches.

This is probably due to two main factors. First, this is a relatively new field of study. Second many risk experts feel uncomfortable with behavioral issues and particularly with the psychological issues of cognitive bias so they stay away from these topics. Clearly this will have to change if risk approaches are to keep up with the times.

But the New Behavioral Models Are Far From Perfect. Some Key Issues Not Yet Addressed: So the new behavioral models open up vast new swathes of territory not only in the economic and financial arena, but also in the arenas of decision-making, risk, talent management and development. They also provide new perspectives on strategy development and implementation. They suggest that too much information can be as dangerous as too little. They provide new ways to improve decisions and to optimize their outcomes in business terms.

But as with any new discipline, they still leave numerous problems unaddressed. This is not a criticism; it is just to state that now these new disciplines have opened up new territory for investigation, they have also allowed new questions to be asked which so far have not been answered and in some cases cannot be answered without more advances in theory and more data from experience. This is the case with the behavioral disciplines.

Some of the problems that are not addressed by behavioral economics and fiancé are the following:

The Problem of Individual Prediction: The behavioral disciplines have identified a rich catalog of cognitive biases and described their effects. Although these effects work at the level of the individual, we can only use them predictively at the level of the group. The new behavioral disciplines provide no model that allows us to predict how these cognitive biases will act in the case of a specific individual, a specific team or a specific company.

We term this problem, the "atomism" problem. We can predict at the level of the organization, say the country, or a large group of consumers. But we cannot make predictions at the level of the individual social atom, the individual, the consumer, the manager, the specific team in a specific company. For the behavioral disciplines to be seen to be more than an academic exercise, they need to address and provide solutions to this problem.

Predicting Precise Business Outcomes: Even more importantly these do not show the actual financial outcome of these cognitive biases for any individual, team or company on business outcomes such as profitability or valuation. Yet it is precisely these issues that are of most interest and utility to shareholders, investors and economists who wish to predict these matters so that the work can have real-world relevance.

We term this problem the "outcome" problem. We need to be able to do more than just say that a particular cognitive bias will distort the outcome of a decision. We need to be able to say how this will happen in practice. In particular we need to be able to couch the outcome in measurable and quantitative terms that are part of the financial and valuation metrics of a company so that we can link behaviors and cognitive biases directly to profitability and capital creation or consumption.

The Problem of Non-Financial Decisions: Not all or even most decisions have an explicit financial element; yet the behavioral disciplines couch their terminology in financial and economic terms, as they must given their intellectual background.

Yet it is clear that cognitive biases impact non-financial and economic outcomes just as much as they do financial and economic outcomes. The behavioral disciplines have done much less to analyze the impact on 
the non-financial arenas. This is because they incorporate a game-theoretic approach, garnered from the game theories of the 1960s which again have a decidedly financial approach.

The Problem of Non-Financial Actors: The behavioral disciplines started their work by focusing on consumers and investors. It was only later that they broadened their focus to corporate managers but even then the focus was on corporate financial managers rather than all managers.

But the work has not yet broadened its reach to actors who are explicitly focused on non-financial issues such as corporate managers of sales for example. Yet it is clear that these players also have an impact on business outcomes through the impact of their cognitive biases.

Just because they are not primary initiators of investment or P\&L managers does not mean they do not have an impact on the overall $\mathrm{P} \& \mathrm{~L}$ of the organization, or on its valuation. That means the cognitive biases of nonfinancial managers must also be included when assessing overall risk.

But the behavioral disciplines are not so comfortable in the non-financial arenas and so have tended to avoid these issues. So these new disciplines so far are more oriented to actors that are explicitly economic and financial actors which limits the applicability of the research to some of the most intriguing and important issues in corporate decision-making and finance.

Atomism and Outcome Problems Most Important: Of the above, the atomism and outcome problems are the two most important. This is because they prevent the theory being operationalized so that it can be used in practice to improve the outcome of decisions. If the aim of a scientific theory is control, then the behavioral decisions are still some way away from this goal. Later in this article we will show some later developments that specifically address these problems and provide some solutions.

Neuroscience and Neuro-Economics Provide Atomistic View. As behavioral economics and finance have emerged and expanded, so has the demand for other types of investigations that would provide increased knowledge on behavior, decision-making and in particular economic and financial decision-making. This new research addresses the issue of the individual level head-on and provides an atomistic perspective that advances the understanding of behaviors at the individual level.

This research relies on MRI, magnetic resonance imaging. This allows scientist to look a brain in real-time to see precisely which areas are impacted when the brain is carrying out certain activities which the subject has been told to think about in advance. These include making decisions on certain matters, or thinking about certain things.

This research aims to elucidate the physical and physiological mechanisms that are involved when decisions are being made or when certain types of thoughts are being played out. The aim is not only to look at physical brain locations involved, but also to look at the types, intensity and frequency of brain waves and other impactors such as changes in brain chemicals and neurotransmitters.

The more general science has been termed neuroscience. This broader approach investigates thoughts, decisions and emotions. The narrower research is called neuroeconomics. The aim of this science is to elucidate physiological mechanisms involved when the brain is making economic and financial decisions and making choices (Neuroeconomics, 2006).

Like neuroscience, neuroeconomics can be experimental in nature so that the fully range of scientific tools can be made and hypotheses investigated. Experimental economics can be combined with neuroeconomics to gain a much deeper appreciation of the biological mechanism involved in economics and financial decisions.

This research also extends to neurochemistry and in particular to the neurochemical oxytocin, the so called love chemical. This research also looks the impact of certain neurochemicals on behaviors, particularly trusting behaviors and their impact in human interactions. While oxytocin has been the hot topic, it is likely that this is just one of a class of neurochemicals that mediate behaviors including financial and economic behaviors and also the mechanisms of choice.

These new channels of research are also opening up new perspectives on economics, finance and decisionmaking, this time from a biological and physiological perspective (Paul W. Glimcher, 2008). However we need to note that these are not cognitive but "wetware" models that give us physical rather than cognitive explanations of decision-making and choice. 
The wetware models do address the atomism issue. They add to the knowledge concerning how to make predictions at the level of the individual, something that we cannot do with current behavioral economics and finance. But these approaches still do not allow us to make predictions about business outcomes, a key requirement for relevance and use in the corporate world and in developing more effective approaches to risk assessment and management.

Recent Empirical Studies Address Behavior and Business Outcome. However there is increasing work which investigates the decision-making characteristics of CEOs and managers and links these to their impact on company financial and valuation performance. One pioneering piece of research by Marianne Bertrand and Antoinette Schoar (Bernadette Schoar, 2003) specifically looks at the managerial characteristics of CEOs to investigate their impact on a wide range of corporate financial variable.

This work finds a high correlation between the two. The authors find that these managerial behaviors can be characterized as distinctive financial styles that have a characteristic and unique impact on company financial metrics and performance. The authors specially note that they are departing from the usual economic approach which is to look at financial outcomes at a firm, industry or market level.

In other words, this study specifically addresses the issues of atomism and outcome in risk behaviors. This work finds high correlations between the two. The literature now shows that the issue of managerial financial style is real and can be correlated statistically with characteristic financial and valuation outcomes. This is a crucial breakthrough from the perspective of risk management. It shows that in principle we can formally link specific individuals with specific financial outcomes and thus assess their level of risk in being associated with those outcomes.

More recent research shows the consistency of financial styles between personal and corporate financial choices on the issue of personal and corporate leverage, again linking financial behaviors with financial outcomes (Cronqvist, 2010). It shows that CEOs' personal financial behavior is at least partially predictive of their companies' financial performance.

In sum, this recent empirical work addresses the issue of business outcome more comprehensively than has been achieved with the classical works of behavioral economics and finance. The problem is that there are no theoretical constructs or models underlying the behavioral side of the problem.

So while wetware and CEO studies address respectively atomism and business outcome, neither address both and link the atomistic level directly with business outcomes in a formal model that simultaneously addresses both. But that issue has now recently been addressed as we shall show in the final part of this paper.

Leadership Training and Business Metrics. Leadership training often incorporates the words "business outcomes". However the problem is that it rarely shows the direct linkages between behavior and business outcomes. Most work on this tends to show that a high level of investment in training leads to positive business outcomes. However it does not show any direct linkage. So a lot of this research lacks credibility since it cannot show a direct linkage (Michael Beer, 2016).

What is becoming clear is that, if leadership training is to have a direct link with business outcomes, it should be linked with business performance metrics, not just outcomes, broadly defined. This point has been emphasized in a report by McKinsey which indicates that the training must incorporate key business performance metrics in order to have the effect that most organizations desire (Cermak, 2010). In other words, training in risk analysis and management should also do the same thing.

Of course, this would require a major shift in risk management curricula. But the weight of evidence is that even talk about business outcomes is not enough if the training and development does not also link directly to behavioral factors and cognitive biases.

\section{Part 3 The Perth Model Provides The Missing Link}

Financial Signatures Address Atomism. The Perth Risk Outcome Model is so-called since it is concerned only with the outcome of behavior, not the behavior itself (Prince, 2005). It defines outcomes in financial and valuation terms (Prince, 2008). This model addresses both the issue of atomism and the issue of business outcome in a formal model that categorizes the types of financial behaviors and the financial and valuation outcomes that flow from them. 
The research is based on fieldwork with some several hundred CEOs and then with numerous other senior executives. It is based on the observation that we all have individual financial traits. These financial traits lie deep within us, so we shall call them innate. These financial traits constitute an internal calculus which drives how each of us approaches decisions involving risk and reward and cost and benefit. They imprint themselves on all of our decisions, in the vast majority of cases without us knowing this.

The research shows that there are distinct behavioral patterns which reflect different ways that individuals are driven by these internal factors to create financial value. These behavior patterns are called financial signatures. The research has identified nine financial signatures which we show below.

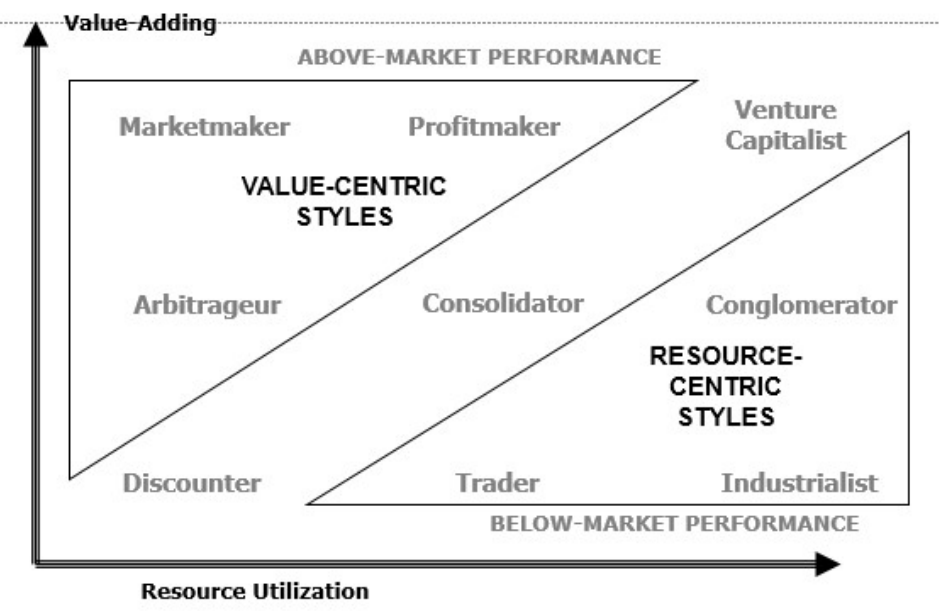

Figure 1. The Nine Financial Signatures

These financial behavior patterns, or financial signatures, are composed of two dimensions of financial traits. These are the propensity to utilize resources to a greater or lesser degree in achieving business goals, and the propensity to add commercial value to products or services, again in achieving business goals.

Each financial signature is in effect a personalized and at least a partly irrational response to a financial situation which imposes a systematic and predictable bias on all of our financial decisions. Thus individual behavior and individual cognitive effects have led the decision to be at least partly irrational in the particular manner which is dictated by the particular position that the manager occupies on the above diagram. Thus the model is one that incorporates the cognitive biases of the individual concerning the factors of value-adding and resource utilization.

And Provide a Formal Model of Business Outcome. The resulting financial signature shows us the behavioral propensity of an individual to generate capital to a greater or lesser extent. In the diagram, financial signatures to the upper left generate more capital since their propensity to add relatively high amounts of value more than outweighs the resources they are behaviorally inclined to consume in achieving this value. On the other hand, on the right hand lower side of the diagram, individuals will be using a level of resources which generally will not be outweighed by the value-added contribution, which will lead to the generation of less or even the consumption of capital.

Financial signatures represent the most basic level of financial behavior. These can be grouped into styles which aggregate the signatures into a higher level representing the financial impact of these styles.

We can divide the nine financial signatures into three financial styles based on this diagram. These are the Value-Centric, Balanced and Resource-Centric styles. The first will tend to outperform the market and the last to under-perform while the balanced styles will perform at the market level.

Thus financial signature and style can tell us not only about the level of individual performance we can expect, but what will happen if a company is composed mainly of a particular financial signature or style relative to its close competitors and to the market it participates in as a whole.

The Model is Measurable in Business Terms. Perth has developed instruments to identify and measure financial signature, most notably its Financial Outcome Assessment instrument. This has been given to almost 1,000 participants. Results show that most people cluster to the lower right of the financial signature chart.

Most managers have financial signatures that lead them to under-perform the market and either to generate 
less capital than their close competitors or to consume it. This pattern prevails even at high executive levels and so far the research has not been able to find a statistical difference in financial signature between executives and other levels.

This parallels work done in other risk studies which shows that on both personality and competency tests, there are no significant differences between managers at widely different levels (Hogan, 2006). It also provides a more scientific underpinning for studies that show that few risk analysts consistently make money and that the vast majority fail as risk analysts, on both straight risk and financial results grounds.

The value-added dimension of financial style is reflected in the gross margin of a unit or enterprise relative to other similar units or close competitors. That is, this accounting measure is a true measure of value-added, both at a corporate and at a behavioral level. We use this measure and not profitability since the latter does not measure value-added. It was not designed to do so, and in any case is too prone to manipulation to be useful.

Similarly the resource utilization dimension of financial style is reflected in the level of indirect expenses relative to other units doing similar work or to close competitors. Once again we need to convert this to a percentage of revenue to allow comparison with other units in the organization and with close competitors.

By adopting this approach, we can calculate the financial mission of the unit or enterprise and compare it to its competitors. This will show the relative positions of the enterprises in a market from the viewpoint of their financial mission.

If financial signature leads to a systematic bias to financial decisions either by individuals or teams, we would expect this to be reflected in the valuation of a company. Our original research found such an impact. Basically the Value-Centric financial styles lead to relatively high growth and high capital generation over the longerterm, since the value-added impact of the style more than outweighs the resources utilized in its achievement. The reverse is true for the Resource-Centric styles which lead to relatively low growth over the longer-term and thus relatively low or negative capital generation.

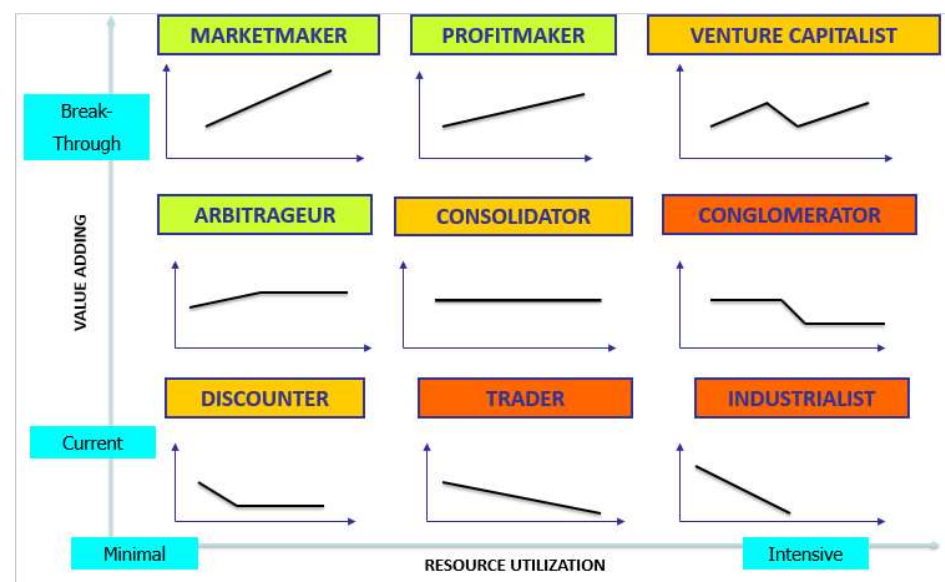

Figure 2. The Nine Valuation Trajectories

The Perth model addresses corporate and microeconomic issues and decision-making via the concept of the financial signature and the associated valuation outcome. It addresses macro-economic and regional and national decision-making via the aggregation of these signatures at the appropriate social levels. The cognitive biases it addresses can be measured both psychometrically through assessments and financially as reflected in the financial statements of a company.

The Perth approach does takes behavioral finance a major step forward by enabling prediction to be carried out at the level of a specific individual, team or company and to predict the precise financial and valuation outcomes that will flow from these decisions.

The approach is measurable and able to be operationalized so that it provides results that can be falsified, the major criterion of a scientific method.

Providing an Atomistic-Outcome Behavioral Synthesis. The Perth model is strictly concerned with business outcomes. They must be measured in terms of their value and valuation impact. 
Risk only has an impact if it impacts business outcomes. Anything else may be a valuable outcome but unless it impacts profitability value and valuation measured in financial terms, it is not a criterion for deciding if risk has been successful or not

The Perth model leads to a new type of synthesis between behavior, business outcomes and risk. This results in the following principles:

Risk is valuation; we can only measure risk through its results; risk can only be said to be successful if the valuation of the unit, team or enterprise increases relative to its competitors.

Valuation is outcome: In any organization, its valuation relative to its competitors drives its outcome. This valuation may be measured in financial or non-financial terms both quantitative and qualitative, such as in nonprofits or a governmental organization.

Valuation is behavior: Valuation is not profitability, assets, sales or intellectual property; these are merely symptoms of behavior. The financial metrics which measure these quantities are merely measuring the results of behavior and they should not be confused with behavior or valuation itself.

All employees have a virtual P\&L: every employee contributes to the valuation of an enterprise, even if they are not aware of that fact. Each of them has a virtual P\&L, whether or not it is recorded. The job of all employees is to increase their own virtual P\&L so that they increase the valuation of their unit, team or enterprise.

All decisions have a value impact: Even if the decision is not explicitly financial in nature, it will have a value impact since it comprises two drivers, value-adding and resource utilization. These may be measured in financial or objective or in qualitative or non-financial terms.

\section{Part 4. The Direct Link Between Cognitive Biases and Profitability}

The Behavioral ProFormaTM. Perth's assessments predict the impact on financial outcomes of the behavior of an individual or a team. However the assessments provide this information in a qualitative manner. Fin$\mathrm{Sim}^{\mathrm{TM}}$ is an initiative to extend this approach so that the assessments can provide quantitative financial forecasts resulting from the behavior of an individual or a team.

In particular the aim is to provide a forecasted income statement in standard format that will be produced from the assessment results of people who complete Perth's assessments, in particular the Financial Outcome Assessment.

The development of FinSim ${ }^{\mathrm{TM}}$ has taken a phased approach. FinSim ${ }^{\mathrm{TM}}$ Mark 1 provides a static income statement. That is, it calculates an income statement that forecasts all major income statement items except sales. That is, it forecasts gross margin, COGS and indirect expenses. It provides actual dollar amounts. These are based on norming a company's current results against its relative industry performance and then linking this to the Financial Signature ${ }^{\circledR}$ of the individual or team. This results in the Behavioral Proforma ${ }^{\mathrm{TM}}$. This forecast provides dollar amounts for profitability and valuation. However the sales number has to be estimated manually and input manually.

FinSim ${ }^{\mathrm{TM}}$ Mark 2 takes this one major step forward. That is, it provides a dynamic income statement. The product provides forecasts of future sales as well as all the other metrics in an income statement. In FinSim ${ }^{\mathrm{TM}}$ Mark 2 the model will provide an estimate of sales based on normed industry metrics which are linked to Perth's behavioral metrics. FinSim ${ }^{\mathrm{TM}}$ Mark 2 still retains the capability of being able to accept manual input of sales figures to allow for sensitivity estimates to be made.

FinSim ${ }^{\mathrm{TM}}$ Mark 2 actually uses two complementary but different approaches to produce sales forecasts. The first calculation channel forecasts short-term sales. The second channel forecasts long-term sales. These two channels are independent and based on different metrics.

In order to differentiate between short- and long-term sales, Perth uses the concept of the product cycle. Sales changes within a product cycle are differentiated from sales outside the existing product cycle, thus allowing for the creation of new products and services impacting sale figures.

The model allows for the input of the product cycle length since this will vary widely between industries. However the default product cycle in FinSim ${ }^{\mathrm{TM}}$ Mark 2 is 3 years. So the overall model produces two sets of forecasts. One is short-term, at the end of the current product cycle. The second is long-term, at the end of the new product cycle following the existing product cycle. 


\section{Your Income Statement}

\section{- Same Behavior As Now}

Your Financial Profile Summary showed you your Financial Mission, that is, the financial behaviors that you are actually using right now.

\section{Your Financial Mission is a INDUSTRIALIST}

If you continue to use these same behaviors, your income statement will look like the one on the right, keeping sales revenues constant.

If this income statement is meeting the objectives of your organization, then it would be appropriate to stay with your current Financial Mission

If the income statement is not meeting the objectives of your organization, or it is not meeting your own objectives, you need to change your behaviors.

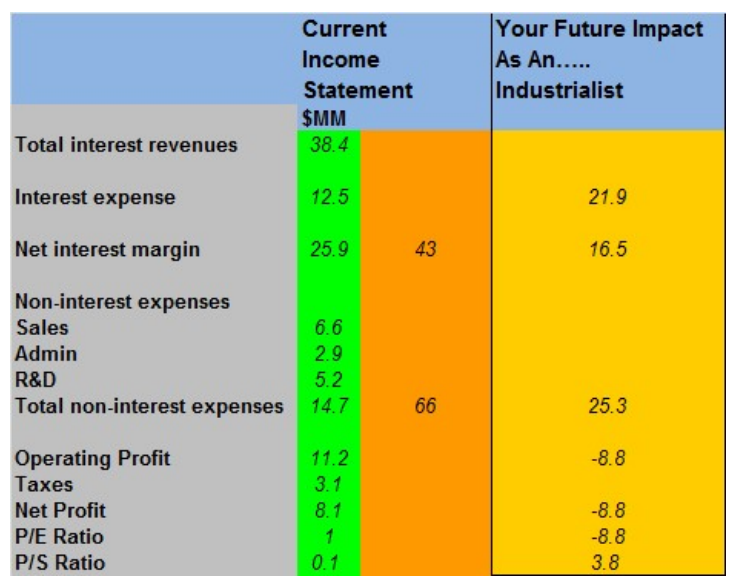

Figure 3. Behavioral ProForma

Behavioral ProForma Sensitivity Analysis. We can take this analysis further since we already have data from the assessments regarding various aspects of the participant's behaviors. We can prepare these Behavioral ProFormas and income statements for the following situations:

If he follows innate behaviors

If he follows current behaviors

If he follows the current behaviors of his company

If he follows recommended behaviors

FINANCIAL RESULTS BEHAVIORAL SENSITIVITY ANALYSIS

\begin{tabular}{|c|c|c|c|c|c|}
\hline Whose Behavior & - Individual & - Individual2 & - Teaml & - Overall & -YYour \\
\hline & $\begin{array}{l}\text { Innate } \\
\text { Behayjor }\end{array}$ & $\begin{array}{l}\text { Current } \\
\text { Betayior }\end{array}$ & $\begin{array}{l}\text { Organization } \\
\text { Behayios }\end{array}$ & $\begin{array}{l}\text { Company } \\
\text { Behavior }\end{array}$ & $\begin{array}{l}\text { Optimum } \\
\text { Behayior }\end{array}$ \\
\hline & & & & & \\
\hline \multirow[t]{2}{*}{ Behavioral Style } & Financial & Financial & Financial & Financial & Financial \\
\hline & Mission & Signature $^{\circ}$ & Mission & Mission & Mission \\
\hline Financial Signature & Conglomerator & Industrialist & Conglomerator & Profitmaker & Profitmaker \\
\hline \multicolumn{6}{|l|}{ Total interest \& other revenues } \\
\hline Interest expense & 38.4 & 38.4 & 38.4 & 38.4 & 38.4 \\
\hline & 19.2 & 21.9 & 19.2 & 13.1 & 13.1 \\
\hline \multicolumn{6}{|l|}{ Net interest margin } \\
\hline Total non-interest expenses & 19.2 & 16.5 & 19.2 & 25.3 & 25.3 \\
\hline & 25.3 & 25.3 & 25.3 & 18.0 & 18.0 \\
\hline \multicolumn{6}{|l|}{ Operating Profit } \\
\hline & -6.1 & -8.8 & -6.1 & 7.3 & 7.3 \\
\hline \multicolumn{6}{|l|}{ Value based on P/E } \\
\hline Value based on P/S & -12.3 & $\begin{array}{r}-8.8 \\
3.8\end{array}$ & -12.3 & 145.9 & 145.9 \\
\hline & 13.4 & 3.8 & 13.4 & 307.2 & 307.2 \\
\hline
\end{tabular}

Figure 4. Behavioral Sensitivity Analysis

As can be seen, now it is possible to examine the income statements and profitability of either a leader or a team under different behavioral scenarios. We can use this to predict actual dollar figures for each of the main income statement categories. Using this analysis we can also construct valuation tables under the different behavioral scenarios, and the different levels of market capitalization associated with each behavioral scenario. 


\section{Conclusion}

Cognitive biases are a bedrock concept in the emerging disciplines of behavioral economics and finance. They exhibit the limits of rationality and the limitations on traditional theories of economics and decision sciences. They have yet to be taken formally into account in developing a modern approach to risk management which takes irrationality formally into account.

We have developed a model and conducted field work with CEOs and top executives to test out a subset of these cognitive biases, and related them to financial outcomes. As can be seen, we can link cognitive biases directly to financial and profitability outcomes. By showing the link between the two we can construct risk models based on behavior. We can call this Behavioral Risk Management or BRM. BRM is not designed to replace traditional risk models but to supplement them with a different perspective and different data. In that way we can formally integrate behavior into risk models to make them more effective.

This article believes that this is the next big step in risk analysis and management. It takes into account the irrationality and cognitive biases that have not been included so far. It takes account of the latest findings in behavioral economics and behavioral finance. It can be operationalized using traditional financial metrics which are routinely captured in income statements and balance sheets. As such this work should be of immediately practical significance for working executives, managers and financial analysts as well as for academic economics and financial researchers.

\section{References}

1. Michelle Park Lazette. (2017, December 18). Recession Retrospective, Federal Reserve Bank of Cleveland. Available at: https://www.clevelandfed.org/newsroom-and-events/multimedia-storytelling/recession-retrospective.aspx

2. Douglas W. Hubbard. (2009). The Failure of Risk Management: Why It's Broken and How to Fix It, Wiley, ISBN: 978-0-470-38795-5. Available at: https://www.wiley.com/en-us/The+Failure+of+Risk+ Management $\% 3 \mathrm{~A}+\mathrm{Why}+\mathrm{It} \% 27 \mathrm{~s}+$ Broken+and+How+to+Fix + It-p-9780470387955

3. John Weinberg. (2013). Federal Reserve History, The Great Recession and its Aftermath: Federal Reserve Bank of Richmond. Available at: https://www.federalreservehistory.org/essays/great recession and its aftermath

4. Mark A. Calabria. (2015). The Dodd-Frank Act Five Years Later: Are We More Stable? Testimony in front of Committee on Financial Services, United States House of Representatives. Available at: https://www.cato.org/publications/testimony/dodd-frank-act-five-years-later-are-we-more-stable

5. FinanceFeeds, Deutsche Bank Chief Risk Officer plays down $£ 41$ trillion derivatives exposure - Is bank looking for an exit from electronic markets? Available at: https://financefeeds.com/deutsche-bank-chiefrisk-officer-plays-down-41-trillion-derivatives-exposure-is-bank-looking-for-an-exit-from-electronicmarkets/

6. Gerold Grasshoff, Thomas Pfuhler, Matteo Coppola, Zubin Mogul, Valerie Villafranca, Norbert Gittfried, Carsten Wiegand. (2018). Global Risk 2018: Future-Proofing the Bank Risk Agenda, Boston Consulting Group. Available at: https://www.bcg.com/publications/2018/global-risk-2018-future-proofing-bankagenda.aspx

7. Macroprudential policy issues arising from low interest rates and structural changes in the EU financial system, November 2016, Joint Task Force of ESRB Advisory Technical Committee (ATC), ESRB Advisory Scientific Committee (ASC), and ECB Financial Stability Committee (FSC). Available at: https://www.esrb.europa.eu/pub/pdf/reports/161128 low interest rate report.en.pdf

8. Silvio Contessi , Usa Kerdnunvong, Asset Bubbles: Detecting and Measuring Them Are Not Easy Tasks, Federal Reserve Bank of St. Louis, July 2015. Available at: https://www.stlouisfed.org/publications/regional-economist/july-2015/asset-bubbles-detecting-and-measuring-them-are-not-easy-tasks

9. Knowledge@Wharton, Is Europe Headed for a Banking Crisis in 2017? January 19, 2017. Available at: http://knowledge.wharton.upenn.edu/article/is-europe-headed-for-a-political-and-financial-crisis-in$2017 /$

10. Ioana A. Duca, Geoff Kenny, Andreas Reuter. (2016). How do inflation expectations impact consumer behaviour?, European Central Bank, European Commision DG-ECFIN. Available at: https://ec.europa.eu/info/sites/info/files/file import/8 geoff kenny ecb paper $0 . p d f$

11. Simona-Valeria Toma, Mioara Chiti, Daniela Sarpe. (2012). Risk and Uncertainty, Procedia Economics and Finance, 3, 975 - 980, Elsevier, doi: 10.1016/S2212-5671(12), 00260-2. Available at: https://ac.els- 
cdn.com/S2212567112002602/1-s2.0-S2212567112002602-main.pdf? tid=8a14b685-9617-4a11-a48381a8a3299603\&acdnat $=1524445907$ 1 ccbdbb9fbc63f937d5c7f4fd554c09a

12. David W. Blackwell, Mark D. Griffiths, Drew B. Winters, Modern Financial Markets: Prices, Yields, and Risk Analysis, Wiley, ISBN: 978-0-470-00010-6, Dec 2006, https://www.wiley.com/en-us/Modern+Financial+Markets\%3A+Prices\%2C+Yields\%2C+and+Risk+Analysis-p-9780470000106

13. Hersh Shefrin. (2015). Behavioral Risk Management: Managing the Psychology That Drives Decisions and Influences Operational Risk, Palgrave Macmillan, London, https://www.palgrave.com/us/media-centre/press/behavioral-risk-management/6639608

14. Dan Ariely. (2009). The End of Rational Economics, Harvard Business Review. Available at: https://hbr.org/2009/07/the-end-of-rational-economics

15. Speech by Chairman Ben S. Bernanke. (2010). Implications of the Financial Crisis for Economics,. At the Conference Co-sponsored by the Center for Economic Policy Studies and the Bendheim Center for Finance, Princeton University, Princeton, New Jersey. Available at: https://www.federalreserve.gov/ newsevents/speech/bernanke20100924a.htm

16. Piotr Kaminski, Daniel Mikkelsen, Thomas Poppensieker, and Kate Robu. (2017). Sustainable compliance: Seven steps toward effectiveness and efficiency, McKinsey \& Company, Risk.. Available at: https://www.mckinsey.com/business-functions/risk/our-insights/sustainable-compliance-seven-steps-toward-effectiveness-and-efficiency

17. Terje Aven. (2015). Implications of black swans to the foundations and practice of risk assessment and management, Reliability Engineering \& System Safety, 134, 83-91. Available at: https://doi.org/10.1016/j.ress.2014.10.004

18. Editors: Anthony Tarantino, Governance, Risk, and Compliance Handbook: Technology, Finance, Environmental, and International Guidance and Best Practices, Copyright (C) 2008 John Wiley \& Sons, Inc. All rights reserved. 5 January 2012, Print ISBN:9780470095898 |Online ISBN:9781118269213 |DOI:10.1002/9781118269213. Available at: https://onlinelibrary.wiley.com/doi/book/ 10.1002/ 9781118269213

19. Sridhar Ramamoorti and Barry Epstein. (2016). Today's Fraud Risk Models Lack Personality: Auditing with 'Dark Triad' Individuals in the Executive Ranks, The CPA Journal. Available at: https://www.cpajournal.com/2016/03/16/todays-fraud-risk-models-lack-personality/

20. Morgeson, F.P., Campion, M.A., Dipboye, R.L., Hollenbeck, J.R. Murphy, K. Schmitt, N., (2007). Reconsidering the Use of Personality Tests In Selection Contexts," Personnel Psychology, 60, 683-729. Available at: http://onlinelibrary.wiley.com/doi/10.1111/j.1744-6570.2007.00089.x/abstract?userIsAuthenticated $=$ false $\&$ deniedAccessCustomisedMessage $=$

21. George P. Hollenbeck, Morgan W. McCall Jr, . Robert F. Silzer. (2006). Leadership competency models, The Leadership Quarterly 398-413, Available at: http://intra.pare.ee/files/Hollenbeck\%20et\%20al\%202006 KMte\%20v\%C3\%A4\%C3\%A4rtus\%20(3) 0. pdf

22. See for example Kari Olsen, Kelsey K. Dworkis, S. Mark Young.( 2013). CEO Narcissism and Accounting: A Picture of Profits. Journal of Management Accounting Research, 131017123325008 DOI: 10.2308/jmar-50638. Available at: https://www.sciencedaily.com/releases/2014/07/140724134027.htm

23. Richard L. Priem, Abdul M.A. Rasheed, Andrew G. Kotulic. (1995). Rationality in Strategic Decision Processes, Environmental Dynamism and Firm Performance, Journal of Management. Available at: http://journals.sagepub.com/doi/abs/10.1177/014920639502100506

24. See for example Schilirò, Daniele. (2011). Economics and psychology.Perfect rationality versus bounded rationality, MPRA Paper 34292, University Library of Munich, Germany. Available at: https://ideas.repec.org/p/pra/mprapa/34292.html

25. Sveinn Vidar Gudmundsson and C. Lechner. (2013). Cognitive Biases, Organization, and Entrepreneurial Firm Survival, European Management Journal, 31(3):278-294, DOI: 10.2139/ssrn.2186062. Available at: https://www.researchgate.net/publication/255725144_Cognitive Biases Organization and Entrepreneurial Firm Survival

26. Daniel Kahneman and Amos Tversky. (1979). Prospect Theory: An Analysis of Decision under Risk, Econometrica, 47(2), 263-291. Available at: https:/www.princeton.edu/ kahneman/docs/Publications/prospect theory.pdf

27. Konstantinos V. Katsikopoulos. (2014). Bounded rationality: the two cultures, Journal of Economic Methodology, 21, 361-374. Available at: https://doi.org/10.1080/1350178X.2014.965908

28. McKinsey Quarterly March 2010, The case for behavioral strategy, By Dan Lovallo and Olivier Sibony, http://www.mckinsey.com/business-functions/strategy-and-corporate-finance/our-insights/the-case-for- 
behavioral-strategy

29. McKinsey. (2010). The case for behavioral strategy. Available at: http://www.mckinsey.com/businessfunctions/strategy-and-corporate-finance/our-insights/the-case-for-behavioral-strategy

30. Tomer Hochma. (2017). The Ultimate List of Cognitive Biases: Why Humans Make Irrational Decisions, Human How: Behavioral Economics in Practice. Available at: http://humanhow.com/en/list-of-cognitivebiases-with-examples/

31. Judgment under Uncertainty: Heuristics and Biases, Amos Tversky; Daniel Kahneman. Science, New Series, Vol. 185, No. 4157. (1974). 1124-1131. Available at: http://links.jstor.org/sici?sici=00368075\%2819740927\%293\%3A185\%3A4157\%3C1124\%3AJUUHAB\%3E2.0.CO\%3B2-M

32. Richard A. Posner, (2013). Behavioral Finance Before Kahneman, 44 Loyola University Chicago Law Journal 1341. Available at: https://chicagounbound.uchicago.edu/cgi/viewcontent.cgi?article=4935\&context $=$ journal articles

33. Daniel Kahneman and Amos Tversky. (1979). Prospect Theory: An Analysis of Decision under Risk, Econometrica, 47(2), 263-291. Available at: https:/www.princeton.edu/ kahneman/docs/Publications/prospect theory.pdf

34. Neuroeconomics: cross-currents in research on decision-making, Alan G. Sanfey, George Loewenstein, Samuel M. McClure and Jonathan D. Cohen. (2006). RENDS in Cognitive Sciences, 10(3). Available at: http://worthylab.tamu.edu/Courses_files/07_Sanfeyetal_2006.pdf

35. Paul W. Glimcher (Editor), Ernst Fehr (Editor), Colin Camerer (Editor), Russell Alan Poldrack (Editor). (2008). Neuroeconomics: Decision Making and the Brain, 1st Edition, Academic Press. Available at: https://www.amazon.com/Neuroeconomics-Decision-Paul-W-Glimcher/dp/0123741769

36. Bernadette Schoar. (2003). Managing with Style: The Effect of Managers on Firm Policies"; Quarterly Journal of Economics, 118(4), 1169-208. Available at: http://qje.oxfordjournals.org/content/118/4/ 1169.short

37. Cronqvist, H, Makhija, A. K., Scott E. Yonker, S.E. (2010). Behavioral Consistency in Corporate Finance: CEO Personal and Corporate Leverage. Available at: http://74.125.155.132/scholar?q= :yO5GnN9KuNoJ:scholar.google.com $/ \& h l=e n \& a s \_s d t=40005 \&$ sciodt $=40000$

38. Michael Beer, Magnus Finnström, Derek Schrader. (2016). Why Leadership Training Fails — and What to Do About It, Harvard Business Review. Available at: https://hbr.org/2016/10/why-leadership-trainingfails-and-what-to-do-about-it

39. Cermak, J., McGurk, M. (2010). Putting a Value on Training, McKinsey Quarterly. Available at: http://www.mckinsey.com/business-functions/organization/our-insights/putting-a-value-on-training

40. Prince, E. Ted. (2005). The Three Financial Styles of Very Successful Risk analysts, McGraw-Hill, New York. Available at: https://www.amazon.com/Three-Financial-Styles-Successful-Leaders/dp/ $0071454292 / \mathrm{ref}=\mathrm{sr} 13$ ? $\mathrm{s}=$ books\&ie=UTF8\&qid=1475619667\&sr=1-3\&keywords=e. + ted + prince

41. Prince, E. Ted. (2008). Research Note: How the Financial Styles of Managers Impact Financial and Valuation Metrics" Review of Accounting and Finance, 7(2), 193-205. Available at: http://www.emeraldinsight.com/doi/abs/10.1108/14757700810874155

42. Hogan, Robert. (2006). Personality and the Fate of Organizations. New Jersey: Lawrence Erlbaum, 41. Available at: http://onlinelibrary.wiley.com/doi/10.1111/j.1744-6570.2007.00101 2.x/abstract

43. Ibid, Lucier, C., Kocourek, P. and Habbel, R. (2005). The crest of the wave. 2006 Strategy and Business, Summer, 100-113. Available at: https://books.google.com/books?id=pE0seiSimOMC\&pg=PA71\&lpg=PA71\&dq $=$ Lucier,+ C.,+ Kocourek,+ P. + and + Hab-

bel, + R. + CEO\&source $=$ bl\&ots $=$ SCbFL

IdzE\&sig=iPa5H3Uer5F67Sz7GnGmEJTGGgo\&hl=en\&sa=X\&ved=0ahUKEwjqgam1mcLPAhUFaz4KHdH2AAYQ6AEIHjAA\#v=onepage \&q=Lucier $\% 2 \mathrm{C} \% 20 \mathrm{C} . \% 2 \mathrm{C} \% 20 \mathrm{Kocou}-$ rek\%2C\%20P.\%20and\%20Habbel\%2C\%20R.\%20CEO\&f=false 